\title{
MUDANÇAS DE USO DO SOLO NA ZONA DE AMORTECIMENTO DO PARQUE ESTADUAL SERRA DE CALDAS: INFLUÊNCIA PEDOLÓGICA NA PRESERVAÇÃO DA VEGETAÇÃO
}

\author{
Silas Pereira Trindade \\ Universidade Estadual de Goiás - Campus Pires do Rio-GO \\ silaspereiratrindade@gmail.com \\ Rafael de Ávila Rodrigues \\ Universidade Federal de Goiás - Regional Catalão \\ rafael.avila.roodrigues@gmail.com
}

\begin{abstract}
RESUMO
O objetivo desta pesquisa foi analisar as mudanças de uso do solo na Zona de Amortecimento do PESCAN, numa sucessão temporal, decenal, para os anos de 1985, 1995, 2005 e 2015, baseando-se na relação dos remanescentes de vegetação nativa com os sistemas pedológicos regionais, utilizando como metodologia, técnicas de Sensoriamento Remoto e de Geoprocessamento. Os resultados mostraram o importante papel do Parque quanto à preservação do Cerrado dentro da Zona de Amortecimento. Observou-se também a grande diminuição das áreas de vegetação nativa, nos dois primeiros decênios, dos quais, se estabilizaram nos decênios posteriores, em função da unidade de preservação. As áreas com maior conservação de vegetação, além do parque, foram os solos com menor aptidão para agricultura, como os Cambissolos, os Neossolos e os Argissolos, opondo-se aos solos com maior aptidão, no caso os Latossolos, que apresentaram os menores remanescentes de vegetação. Concluiu-se que as unidades de conservação desempenham um importante papel regulador do desflorestamento do Cerrado, mas as Zonas de Amortecimento ainda não possuem grande eficiência preservacionista, sendo expostos ao avanço da racionalidade econômica.
\end{abstract}

Palavras-chave: Parque Estadual Serra de Caldas Novas. Uso do Solo. Técnicas de Sensoriamento Remoto. Vegetação Nativa e Sistemas Pedológicos.

\section{CHANGES IN LAND USE IN THE BUFFER ZONE OF THE SERRA DE CALDAS NOVAS STATE PARK: INFLUENCE OF THE PEDOLOGICAL CARACHTERISTICS ON THE REMNANT VEGETATION}

\begin{abstract}
The objective of this research was to analyze the changes in land use in the buffer zone of the PESCAN, in a decennial time sequence, for the years of 1985, 1995, 2005 and 2015, based on the relation between the remnant native vegetation and the region pedological systems, using techniques of Remote Sensing and Geoprocessing. The results showed an important role of the Park in relation to the preservation of the Cerrado inside the buffer zone. A huge decrease of native vegetation areas was observed too on the first two decennials, stabilizing on the next decennials, due to the preservation unit. The areas with the greatest conservation of vegetation, besides the park, were the soils with the lowest fitness to agriculture, such as the Cambisols, Neosols and Argisols, opposing the soils with greater fitness, the case of the Latosols, which present the lowest remnant vegetation. This phenomenon could be observed through the relation between the Density of the Vegetation per Class of Soil (DVCS), that presented lower rates of DVCS on the best soils. It is concluded that the units of conservation play an important regulative role of the Cerrado deforestation, but the buffer zones do not have a great preservation efficiency yet, being exposed to the advance of rational economy.
\end{abstract}

Keywords: Serra de Caldas NovasState Park. Land Use. Techniques of Remote Sensing. Native Vegetation and Pedological Systems. 


\section{INTRODUÇÃO}

As unidades de conservação foram estabelecidas no Brasil, como política pública, com a Lei Federal 9.985/2000 que instituiu o Sistema Nacional de Unidades de Conservação-SNUC. A promulgação da legislação específica criou referências para a gestão e manejo de áreas que possuem recursos naturais com interesses na manutenção dos recursos bióticos e abióticos (BRASIL, 2000).

Dado o exposto, o Parque Estadual Serra de Caldas Novas-PESCAN, foi criado por meio da Lei n. 7.282 de 25 de setembro de 1970 para proteger diretamente importantes áreas de recargas de aquíferos da região (MENDES, 2007). Além da proteção dessas áreas, as unidades de conservação agregam as Zonas de Amortecimento-ZA, que são áreas estratégicas para paliação dos efeitos das atividades humanas estabelecendo o amortecimento dos habitats naturais, além de manter o uso disciplinado das terras localizadas no entorno das unidades de conservação. (BRASIL, 2000; COSTA, 2002).

Sano et al. (2008), observaram que as áreas de Cerrado registram algum tipo de uso, sobretudo de pastagens e áreas agrícolas. Diante dessas características, as áreas de vegetação natural, na Zona de Amortecimento do PESCAN, vêm passando por mudanças no uso do solo das quais, segundo Silva e Ferreira (2011), desencadeiam grande vulnerabilidade ambiental para a região.

Dessa forma, este processo é associado ao avanço da fronteira agrícola que, a partir das décadas de 1970, deu-se uma nova dinâmica econômica ao padrão agropecuário regional no Cerrado brasileiro. Por meio da frente pioneira e da frente de expansão, surgiram nestas áreas um modelo agroexportador passando a apresentar no meio da formação dos complexos agroindustriais, com ênfase na cadeia produtiva de grãos (MARTINS, 1975; KAGEYAMA, 1996; MIZIARA, 2000). Em face desta dinâmica, a estruturação das bases de um agronegócio industrializado acelerou o processo de desmatamento e a seletividade por melhores solos, dos quais atingem melhores índices produtivos.

A variável pedológica tornou-se um importante elemento influenciador nas condições de desmatamento e de preservação. As áreas de melhor aptidão agrícola, que favorecem as condições de maior produtividade, possuem intenso uso que leva a perda quase que total das áreas de florestas, enquanto que as áreas de menor atratividade econômica são mais preservadas. Esta relação entre solos e vegetação refletem as características do material de origem, conforme mostrado por Silva et al. (2015), quando correlacionaram a influência das áreas de arenito do Grupo Urucuia, em área de Cerrado entre Minas Gerais, Bahia e Goiás, com a fitofisionomia sobreposta e o seu uso restrito.

Em razão disso, a relação entre solos e agricultura destaca as áreas mais aptas e menos aptas para a produção de grãos. Isto cria melhores condições produtivas, das quais tem influenciado no uso dos solos. Ruggiero et al. (2005) destacaram que dentre as fitofisionomias do Cerrado, as mais preservadas, localizavam-se em áreas de Neossolos Quartzarênicos e nos Neossolos Hidromórficos e Flúvicos, áreas de uso restrito para a agricultura comercial devido a sua fragilidade natural e por restrições ambientais. Por outro lado, maior parte das áreas de Latossolos Vermelho-Amarelos e Latossolos Vermelhos, que caracterizam áreas com grande potencial produtivo, apresentaram as menores áreas de remanescentes de vegetação.

Assim sendo, o objetivo desta pesquisa foi analisar as mudanças de uso do solo na zona de amortecimento do Parque Estadual Serra de Caldas, e os seus municípios, numa sucessão temporal, decenal, para os anos de 1985, 1995, 2005 e 2015, destacando-se a relação das áreas com vegetação nativas preservadas e os solos, para averiguar a dinâmica da preservação ambiental por meio da correlação matricial das áreas de remanescentes da vegetação nativa com os sistemas pedológicos e suas aptidões agrícolas do parque e de sua região lindeira.

\section{METODOLOGIA}

O desenvolvimento deste estudo ocorreu em cinco etapas, seguindo os seguintes procedimentos: determinação da Zona de Amortecimento do Parque Estadual Serra de Caldas; elaboração das mudanças de uso do solo; reclassificação do mapa pedológico e o desenvolvimento da aptidão agrícola do uso das terras; análise integrada dos remanescentes florestais com os solos da área lindeira ao PESCAN e o cálculo da densidade de vegetação por classes de solos.

\section{Zona de Amortecimento do Parque Estadual de SerRa de CALDAS}

A Zona de Amortecimento-ZA do PESCAN foi determinada, a partir do Sistema Nacional de Unidades de Conservação (Lei 9.985/2000) e pelo Plano de Manejo da reserva. Baseando-se nos dispostos da legislação vigente, que considera como ZA um raio de $10 \mathrm{~km}$ lindeiros à unidade de conservação, delimitou-se a região de estudo. Esta delimitação foi desenvolvida utilizando a ferramenta buffer do ArcGis versão 10.1, baseando-se na área total do parque contida nas bases cartográficas do Sistema de Informações Estatísticas e Geográficas de Goiás-SIEG/GO.

$\begin{array}{llllll}\text { Caminhos de Geografia } & \text { Uberlândia } & \text { v. 20, n. } 72 & \text { Dezembro/2019 } & \text { p. 01-14 } & \text { Página } 2\end{array}$




\section{MAPAS DE USO DO SOLO}

Os mapas de uso do solo foram elaborados utilizando imagens dos satélites Landsat 5 e Landsat 8. Utilizou-se cenas da sucessão temporal decenal, dos anos de 1985, 1995, 2005 e 2015, tendo como referência a Zona de Amortecimento do PESCAN. O quadro 1 mostra as resoluções temporais, orbitais e espectrais das imagens utilizadas.

Quadro 1- Cenas Landsat 5 e Landsat 8 utilizadas para o mapeamento da zona de amortecimento do PESCAN.

\begin{tabular}{|c|c|c|c|c|}
\hline Ano & Satélite & Órbita e Ponto & Datas & Composição RGB \\
\hline 1985 & \multirow{3}{*}{ Landsat 5 } & \multirow{2}{*}{$221 / 072$} & $26 / 03 / 1985$ & \multirow{2}{*}{ Bandas R(3) G (4) B (5) } \\
\cline { 1 - 1 } 1995 & & $13 / 08 / 1995$ & \multirow{2}{*}{ Bandas R (6) G (5) B (4) } \\
\cline { 1 - 1 } & & $23 / 07 / 2005$ & \\
\hline 2005 & & $221 / 072$ & $16 / 02 / 2015$ & Landsat 8 \\
\cline { 1 - 1 }
\end{tabular}

Fonte: elaborado pelos autores com base na base de imagens do INPE (2016).

As imagens Landsat 5 foram, primeiramente, ortorretificadas, sendo que as Landsat 8 dispensaram tal tratamento, pois já são disponibilizadas georreferenciadas. Em face disso, utilizando-se técnicas de Sensoriamento Remoto e de Geoprocessamento, extraiu-se destas imagens a Zona de Amortecimento, configurando no objetivo deste trabalho. Por sequência, estas áreas foram segmentadas e classificadas seguindo o método de segmentação não-supervisionada e classificador de Bhattacharya com escala de referência de 1:100.000. E para elaborar os mapas de usos dos solos selecionaram-se as seguintes classes de usos: agricultura, pastagem, vegetação nativa, área urbana e água. Após o desenvolvimento dos mapas, extraiu-se as tabelas com as áreas de cada classe de uso em hectares.

\section{MAPA de APTIDÃo AgRícola do USO dAs TERRAS}

Para a confecção do mapa de solos, utilizou-se a base cartográfica do Plano Diretor da Bacia Hidrográfica do Rio Paranaíba em Goiás, disponível no SIEG/GO na escala de 1:250.000. Esta base cartográfica foi reclassificada dentro do Sistema Brasileiro de Classificação dos Solos, até o segundo nível categórico na escala de 1:50.000. Com base nos dados pedológicos descritos, desenvolveu-se o mapa de aptidão agrícola do uso das terras considerando a base metodológica de Ramalho Filho; Beek (1995), que considera a deficiência de fertilidade, deficiência ou excesso de água, suscetibilidade erosiva e impedimentos de mecanização. Assim, como na sucessão de usos dos solos, geraram-se as tabelas com as áreas das classes de solos identificadas na zona de amortecimento, em hectares.

\section{ANÁlISE DA VEGETAÇÃo ASSOCIADA A APTIDÃo AGRÍCOLA}

A análise dos remanescentes florestais e os sistemas pedológicos ocorreu por meio da integração da vegetação nativa, extraída da sucessão de usos do solo, compreendidas diacronicamente entre 1985, 1995, 2005 e 2015, por meio da ferramenta Overlay do ArcGis 10.1, a aptidão agrícola. Após a finalização da integração da vegetação e os solos, gerou-se, no mesmo software, o quadro de áreas em hectares da relação florestas e aptidão.

\section{DENSIDADE DE VEGETAÇÃO POR CLASSES DE APTIDÃo AGRÍCOLA-DVAA}

Para eliminar os efeitos da distorção da interpretação da relação solo e vegetação, em consequência das diferentes áreas das classes pedológicas, estabeleceu-se o cálculo da Densidade de Vegetação por Aptidão Agrícola-DVAA que levou em consideração relação entre a área da vegetação remanescente em cada classe de aptidão pela área total de cada classe, expresso em porcentagem (\%).

\section{RESULTADOS E DISCUSSÃO}

\section{LOCALIZAÇÃO E CARACTERIZAÇÃO FÍSICA DA ÁREA DE ESTUDO}

O Parque Estadual Serra de Caldas Novas abrange uma complexa relação física estruturada no soerguimento regional, por meio do sistema dômico, que resultou no complexo de águas termais que sustenta a economia regional com base no turismo. A criação da unidade de conservação veio para

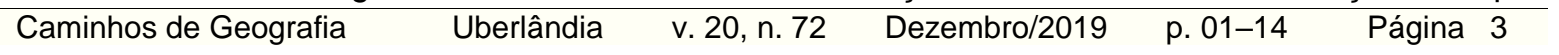


consolidar a preservação dos recursos hídricos por meio do ordenamento territorial do uso do solo, principalmente diante da preservação dos recursos florestais.

A criação do PESCAN ocorreu em 1970 com o objetivo de preservar, das ações antrópicas, a região conhecida como Domo Estrutural de Caldas, Domo de Caldas ou Serra de Caldas, tendo como feição fisiográfica/estrutural de elevação isolada no sudeste goiano que alcança elevações superiores a 1000 metros. Esta área possui aproximadamente 12.315,36 hectares, da qual abriga um dos maiores complexos hidrotermais já conhecidos, com aquecimento hídrico desassociado ao magmatismo, sendo resultado do aumento do grau geotérmico das áreas de recarga do Domo de Caldas (FEMAGO, 1997; CAMPOS, TRÖGER, HAESBAERT, 2009).

O parque se localiza em área de Cerrado brasileiro abrangendo os municípios de Caldas Novas, em sua maior parte, Rio Quente e Marzagão, em menor proporção, no estado de Goiás (Figura 1). Além destes municípios, a sua zona de amortecimento do PESCAN submete a uma área de $85.518,62$ hectares de uso restrito, que abrange pequenas porções, de Morrinhos e Ipameri.

Figura 1 - Mapa de localização do PESCAN-2016.

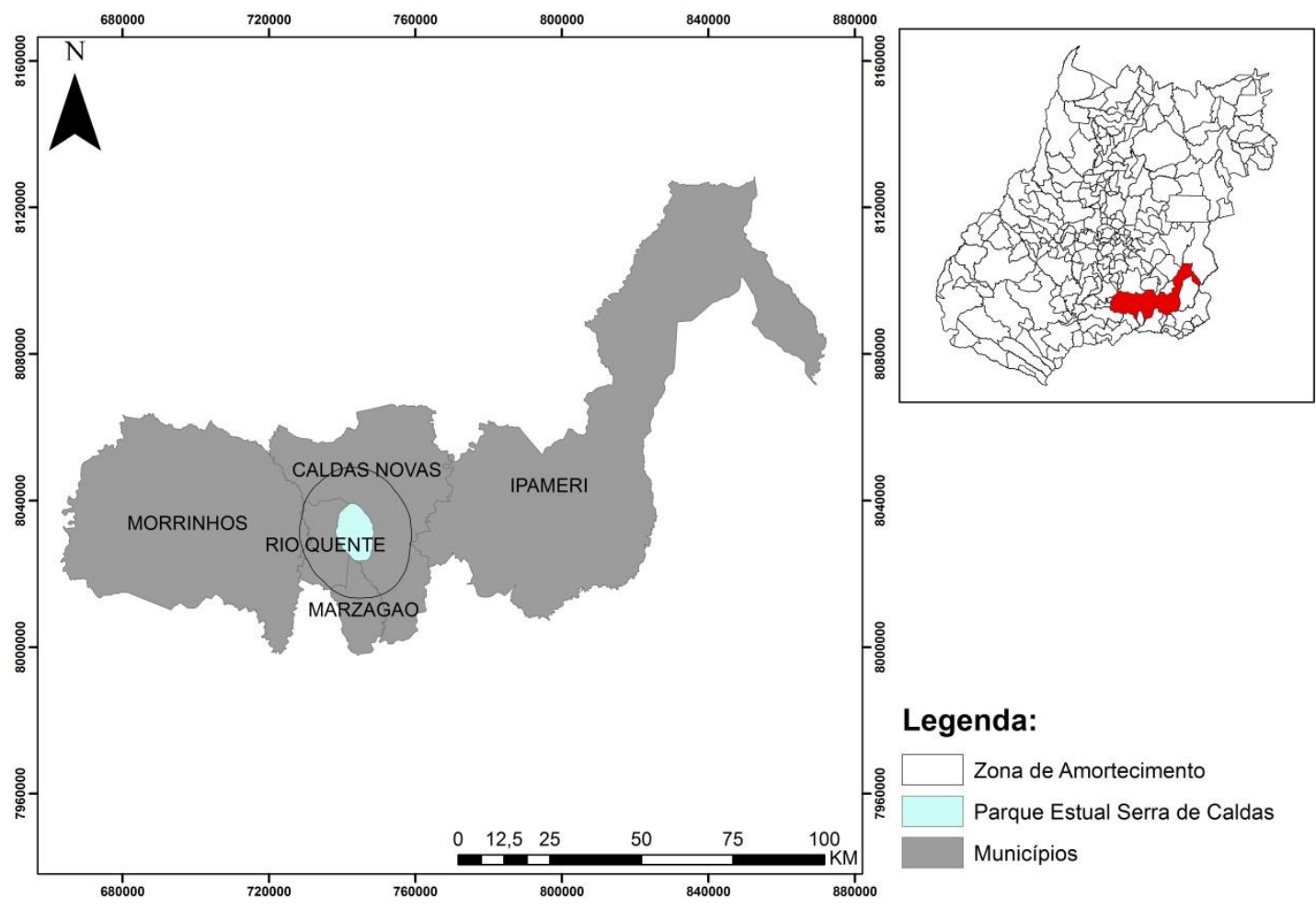

Fonte: Sistemas de Estadual de Geoinformação de Goiás-SIEG.

Devido ao manancial hidrotermal, iniciou-se uma exploração insustentável deste recurso resultando no rebaixamento do lençol e desaparecimento das nascentes regionais, tendo o seu aproveitamento, atualmente, controlado pela instauração de políticas ambientais preservacionistas (CAMPOS, TRÖGER, HAESBAERT, 2009).

A criação do parque trouxe consigo, a concepção das zonas de amortecimento, que são áreas com restrições de usos antrópicos nas regiões lindeiras das unidades de conservação. A criação destas zonas, segundo o Sistema Nacional de Unidades de Conservação (2000), tem a função de minimizar os impactos ambientais negativos dos usos das terras. O Plano de Manejo do PESCAN estabelece uma área de amortecimento com abrangência no raio de 10 quilômetros do parque, selecionando as atividades de exercício proibido, como indústrias gerais poluentes ou semi-poluentes, estações de tratamento de água, esgoto ou disposição de lixo, pistas de pouso, rodovias novas, exploração dos recursos naturais (exceto os hídricos), desmatamentos, criação de novos hotéis, loteamentos sem projetos especiais e poluição sonora (FEMAGO, 1997).

$\begin{array}{llllll}\text { Caminhos de Geografia } & \text { Uberlândia } & \text { v. 20, n. 72 } & \text { Dezembro/2019 } & \text { p. 01-14 } & \text { Página } 4\end{array}$


Desta forma, o monitoramento do uso das terras, na ZA, representa as condições da qualidade ambiental no complexo hidrotermal de Caldas Novas/Rio Quente. Tendo em vista os aspectos apresentados, visualizou-se que a vegetação nativa vem perdendo, ao longo dos tempos, espaço para outras atividades econômicas relacionadas com o meio agropecuário, comprometendo as drenagens visto que, com relação ao meio físico da zona de amortecimento, as áreas florestadas estão predominantes nos locais de baixo potencial econômico, quanto às características dos solos da região.

\section{APTIDÃo AGRÍCOLA NA ZONA DE AMORTECIMENTO DO PESCAN}

A aptidão agrícola das terras representa uma análise integrada de indicação dos melhores usos dos solos. A metodologia da aptidão agrícola analisa as variáveis pedológicas que possam interferir na produção diante dos diferentes níveis de manejo, que vão das práticas agrícolas rudimentares até as de maior uso de tecnologia. São analisadas a deficiência de fertilidade, deficiência ou excesso de água, suscetibilidade erosiva e impedimentos de mecanização. Por meio da hierarquização dos níveis de manejo tecnológico da mecanização, a aptidão agrícola classifica as terras para o uso de lavouras, pastagens plantadas, silvicultura, pastagens naturais e preservação (RAMALHO FILHO; BEEK,1995).

As classes de aptidão predominantes nas áreas de Cerrado goiano são as indicadas para o uso de lavouras, diferenciando-se pela capacidade de mecanização (EMBRAPA, 1989). Essas áreas apresentam um intenso uso do solo voltado para as atividades agrícolas que avançam sobre as áreas de vegetação nativa.

A análise da Zona de Amortecimento do Parque Estadual Serra de Caldas Novas mostrou a distribuição das classes de aptidão agrícola conforme figura 2.

Figura 2 - Mapa da distribuição espacial das classes de aptidão agrícola no entorno do PESCAN.

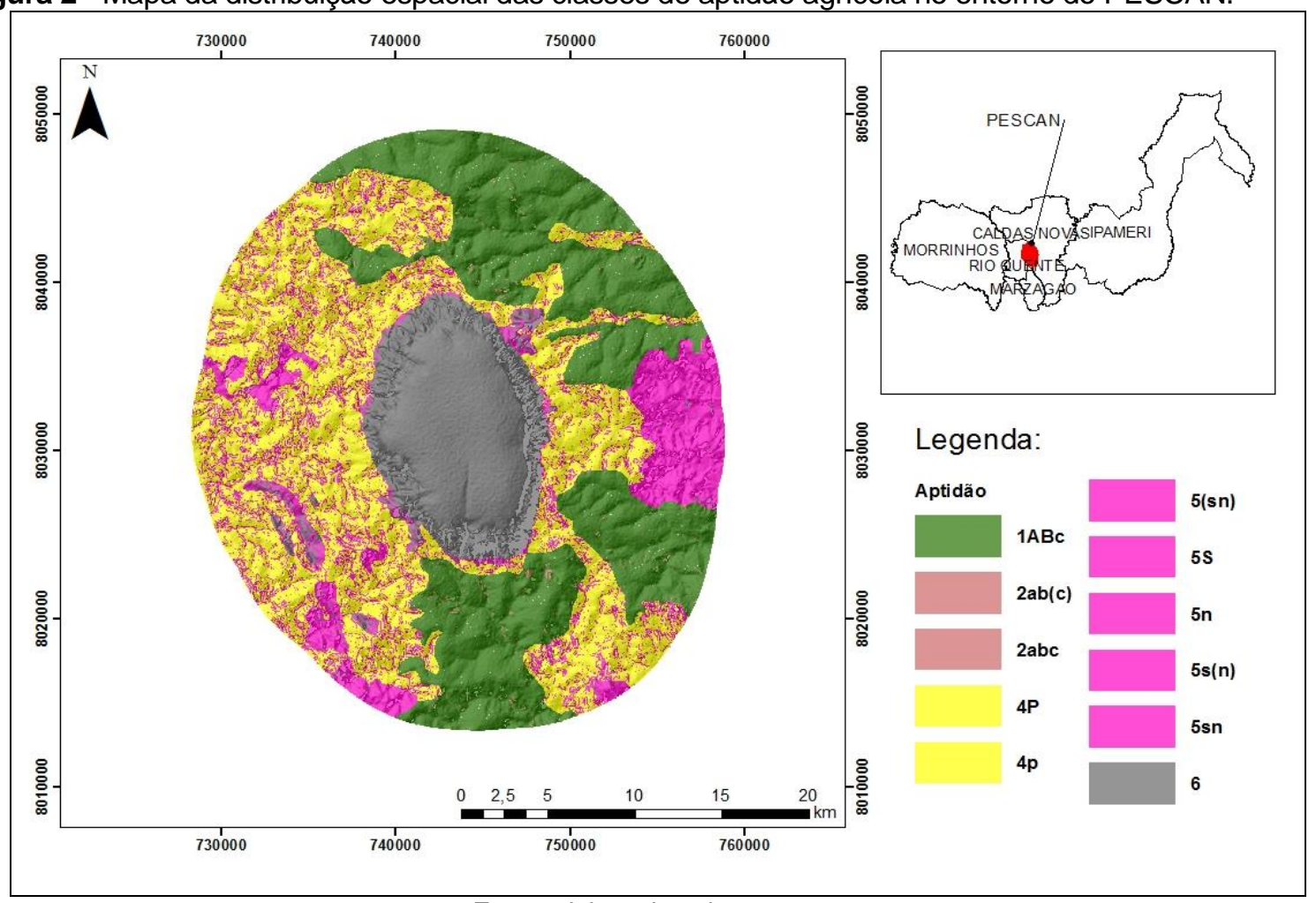

Fonte: elaborado pelos autores.

A área de entorno do PESCAN exibiu a variação de terras indicadas para o uso de lavouras, pastagens plantadas e naturais, silvicultura e para preservação, conforme tabela 2.

$\begin{array}{lllll}\text { Caminhos de Geografia } & \text { Uberlândia } & \text { v. 20, n. } 72 & \text { Dezembro/2019 } & \text { p. 01-14 Página } 5\end{array}$




\section{Tabela 2 - Classes de aptidão agrícola na ZA/PESCAN}

\begin{tabular}{|c|c|c|c|c|}
\hline $\begin{array}{c}\text { Classe } \\
\text { Aptidão }\end{array}$ & Caracterização & Uso & Área & $\%$ \\
\hline $1 \mathrm{ABc}$ & Terras pertencentes à classe de aptidão boa para lavouras nos níveis de manejo $\mathrm{A}$ e $\mathrm{B}$, e regular para o nível $\mathrm{C}$ & & $26.417,93$ & 30,89 \\
\hline $2 \mathrm{ab}(\mathrm{c})$ & Terras pertencentes à classe de aptidão regular para lavouras nos níveis de manejo A e B, e restrita no nível C & Lavouras & 1,94 & 0,00 \\
\hline $2 \mathrm{abc}$ & Terras pertencentes à classe de aptidão regular para lavouras nos níveis de manejo $\mathrm{A}, \mathrm{B}$ e C & & 321,57 & 0,38 \\
\hline Subtotal & & & $26.741,45$ & 31,27 \\
\hline $4 \mathrm{P}$ & Terras pertencentes à classe de aptidão boa para pastagem plantada & Pastagem & $10.837,29$ & 12,67 \\
\hline $5 \mathrm{~S}$ & Terras pertencentes à classe de aptidão boa para silvicultura & & $9.627,63$ & 11,26 \\
\hline $5 \mathrm{n}$ & Terras pertencentes à classe de aptidão regular para pastagem natural e à inapta para silvicultura & Silvicultura e & $6.503,45$ & 7,60 \\
\hline $5 \mathrm{sn}$ & Terras pertencentes à classe de aptidão regular para silvicultura e pastagem natural & pastagem & 147,77 & 0,17 \\
\hline $5 s(n)$ & Terras pertencentes à classe de aptidão regular para silvicultura, e restrita para pastagem natural & natural & 255,10 & 0,30 \\
\hline Total & & & $85.518,62$ & 100,00 \\
\hline
\end{tabular}

Fonte: elaborado pelos autores (2016) a partir dos dados do SIEG.

Caminhos de Geografia Uberlândia $\quad$ v. 20, n. 72 Dezembro/2019 $\quad$ p. 01-14


Por meio da tabela anterior, foi possível observar a distribuição das aptidões agrícolas do uso das terras na área de estudo. Conforme apresentado, há a predominância das áreas aptas para pastagens plantadas $(33,14 \%)$, seguidas pelas áreas de aptidão para lavouras $(31,27 \%)$, as áreas com uso indicado para silvicultura e pastagens naturais $(19,51 \%)$ e as terras sem aptidão agrícola que são voltadas para a preservação (15,50\%).

A classe de uso indicado para pastagens plantadas é subdivida em áreas com terras pertencentes à aptidão regular, representadas pela sigla $4 p$, e pelas terras pertencentes à classe de aptidão boa, representadas pela sigla 4P. O predomínio pedológico dessas áreas está relacionado com 0 predomínio do Argissolo Vermelho-Amarelo com variação na declividade e na suscetibilidade erosiva. As áreas $4 p$ ocupam cerca de 20,47\%, enquanto as áreas 4P ocupam 12,67\% dessa classe.

As áreas de uso indicado para lavouras é composta por áreas de aptidão boa para lavouras nos níveis de manejo $A$ e $B$ e regular para o nível $C$, representadas pela sigla $1 \mathrm{Abc}$, pelas terras de aptidão regular para lavouras nos níveis de manejo $\mathrm{A}$ e $\mathrm{B}$, e restrita no nível $\mathrm{C}$, caracterizada pela sigla $2 \mathrm{ab}(\mathrm{c})$ e pelas áreas de aptidão regular para lavouras nos níveis de manejo $\mathrm{A}, \mathrm{B}$ e $\mathrm{C}$ denominada como 2abc. Nestas áreas predominam os Latossolos Vermelhos com variação em relação a sua suscetibilidade erosiva. A classe de aptidão $1 \mathrm{ABc}$ ocupa cerca de $31 \%$ do total das áreas aptas para lavouras seguidas pela classe $2 \mathrm{abc}$ que apresenta aproximadamente $0,4 \%$, enquanto que a classe $2 \mathrm{ab}(\mathrm{c})$ apresenta valor insignificante.

As áreas com potencial produtivo para a silvicultura e pastagem natural apresentaram o maior número de classes de aptidão. Foi possível identificar as áreas de aptidão boa para silvicultura (5S), as áreas de aptidão regular para pastagem natural e à inapta para silvicultura (5n), as áreas de aptidão regular para silvicultura e pastagem natural (5sn), a classe de aptidão regular para silvicultura $(5 s(n))$, e restrita para pastagem natural e as áreas restrita para silvicultura e pastagem natural $(5(\mathrm{sn}))$. Estas áreas estão associadas aos Argissolos Vermelho-Amarelos, aos Cambissolos Distróficos, Cambissolos Háplicos e aos Neossolos Litólicos. A classe 5S ocupa uma área de 11,26\% do total da classe de aptidão, seguido pela classe $5 n(7,60 \%)$, a $5 s(n)(0,30 \%)$ e as $5 s n$ e $5(s n)$, ambas com $0,17 \%$.

Por fim, as áreas de preservação, compreendidas como ausentes de aptidão agrícola, são representadas pela sigla 6 . Esta classe apresentou menor área, ocupando cerca de $15,50 \%$ da região de estudo. A classe de aptidão voltada para a preservação está relacionada com as restrições de limitações pedológicas que promovem o ordenamento do uso, sendo áreas indicadas para recreação, preservação da fauna e da flora e de outros usos não-agrícolas, por não comportarem atividades de maior intensidade (RAMALHO, FILHO; BEEK, 1995). Diante da importância do PESCAN como unidade de conservação, incluiu-se o parque nesta categoria, visto o seu objetivo conservacionista. As classes de solos Argissolos Vermelho-Amarelo, Latossolos Vermelho-Amarelo, Neossolos Litólicos, Cambissolos Háplicos e Cambissolos Distróficos.

\section{MUdANÇAS de USO do Solo Na Zona de AMORTECIMENTO do PESCAN}

O atual cenário das áreas de Cerrado no Brasil retrata uma evolução da perda da biodiversidade em decorrência da expansão das áreas de agricultura e de pecuária intensiva. O uso do solo, por práticas econômicas, é maior do que as áreas preservadas, ou seja, dos remanescentes de vegetação nativa. Isto submete uma elevada fragmentação do bioma que afeta as condições ecológicas das quais somam como pontos negativos na preservação do Cerrado (FERREIRA; FERREIRA JR.; FERREIRA, 2008).

A sucessão cronológica de uso do solo na área de amortecimento do PESCAN retrata esta realidade por meio dos anos analisados (1985, 1995, 2005 e 2015), conforme observado na figura 3. Nela é possível observar a distribuição das classes de usos juntamente com a dinâmica distributiva segundo a tabela 2. 
Figura 3 - Mudancas de uso do solo no PESCAN dos anos de 1985, 1995, 2005 e 2015.

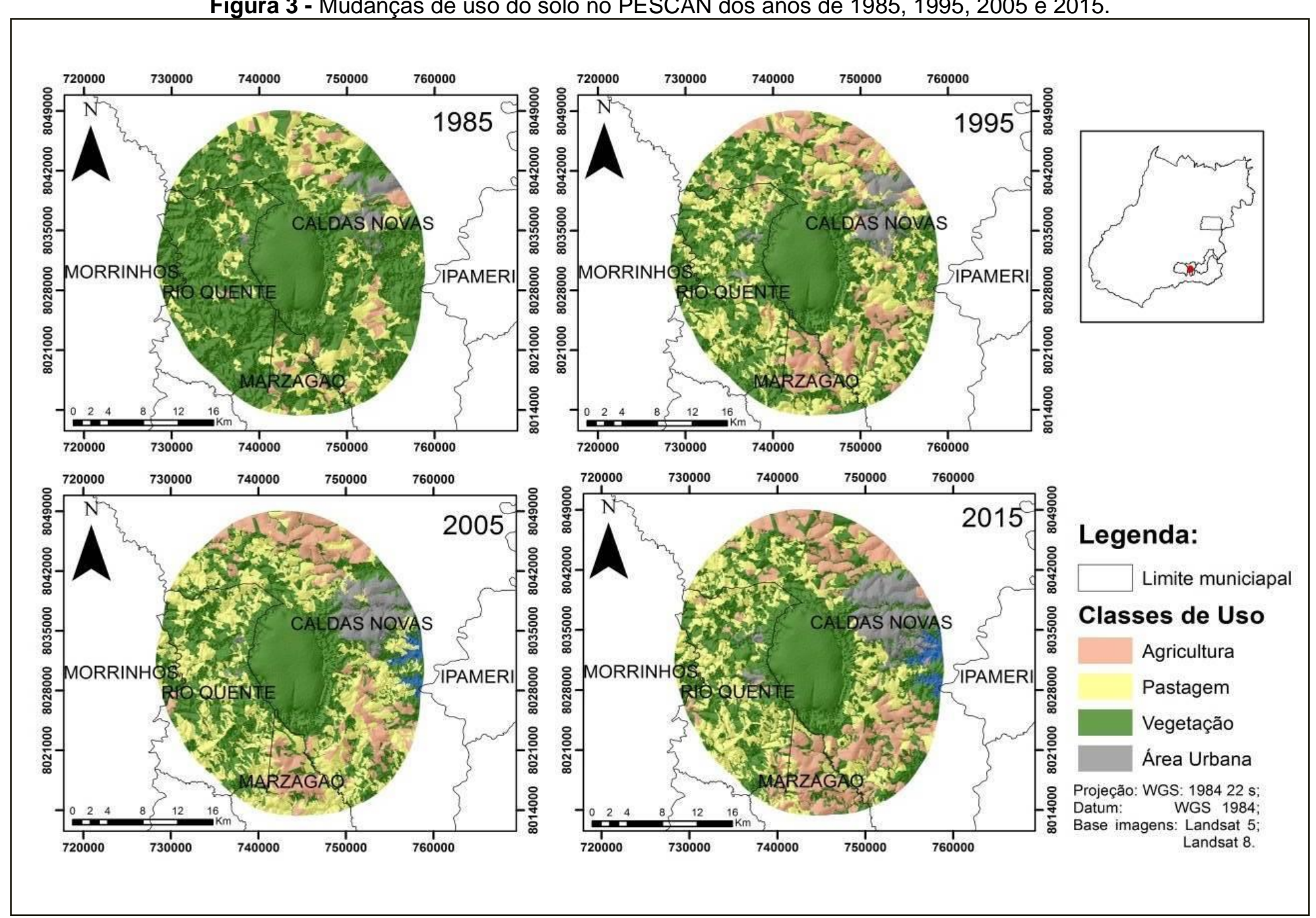

Fonte: elaborado pelos autores (2016). 
Mudanças de uso do solo na zona de amortecimento do

Parque Estadual Serra de Caldas: influência pedológica na preservação da vegetação

Tabela 2 - Distribuição das classes de uso do solo na área de amortecimento do PESCAN em hectares.

\begin{tabular}{ccccccccc}
\hline Uso dos Solos & Área 1985 & $\%$ & Área 1995 & $\%$ & Área 2005 & $\%$ & Área $\mathbf{2 0 1 5}$ & $\%$ \\
\hline Agricultura & $3.780,82$ & 4,42 & $11.052,62$ & 12,92 & $11.032,32$ & 12,90 & $15.478,46$ & 18,10 \\
Pastagem & $17.162,32$ & 20,07 & $26.196,42$ & 30,63 & $28.408,16$ & 33,22 & $21.196,85$ & 24,79 \\
Vegetação & $62.198,30$ & 72,73 & $44.211,67$ & 51,70 & $39.496,91$ & 46,19 & $40.505,78$ & 47,36 \\
Área Urbana & $2.377,18$ & 2,78 & $4.057,90$ & 4,75 & $6.062,92$ & 7,09 & $7.243,67$ & 8,47 \\
Água & 0,00 & 0,00 & 0 & 0 & 518,31 & 0,61 & $1.093,86$ & 1,28 \\
\hline Total & $\mathbf{8 5 . 5 1 8 , 6 2}$ & $\mathbf{1 0 0 , 0 0}$ & $\mathbf{8 5 . 5 1 8 , 6 2}$ & $\mathbf{1 0 0 , 0 0}$ & $\mathbf{8 5 . 5 1 8 , 6 2}$ & $\mathbf{1 0 0 , 0 0}$ & $\mathbf{8 5 . 5 1 8 , 6 2}$ & $\mathbf{1 0 0 , 0 0}$ \\
\hline
\end{tabular}

Fonte: elaborado pelos autores (2016).

A tabela anterior apresenta as principais classes de uso do solo identificadas por meio da relação área e ano analisado. Sendo o primeiro ano analisado, 1985, houve o predomínio da vegetação nativa com $72,73 \%$ da área, seguida pelas pastagens que ocupavam $20,07 \%$ e, o interessante, a agricultura e a área urbana somadas apresentavam apenas $7,2 \%$ do total. $\mathrm{O}$ ano de 1995 repetiu o padrão do predomínio da vegetação nativa, com $51,70 \%$, com consideráveis aumentos nas áreas de pastagens $(30,63 \%)$ e da agricultura $(12,92 \%)$, além de um ligeiro aumento da área urbana com $4,75 \%$ do total. $\mathrm{O}$ ano de 2005 apresentou valores importantes, pois a vegetação nativa, apesar de apresentar constante redução, ainda é a maior classe de uso na região, com $46,19 \%$ do total. No entanto, outras classes que sofreram aumento foram às áreas urbanas e a água, representadas pelo crescimento das cidades $(7,09 \%)$ e pelo surgimento de pequenas massas d'água $(0,61 \%)$. Contudo, as classes das pastagens e da agricultura apresentaram valores muito similares ao período anterior de 10 anos, $33,22 \%$ e 12,90\% respectivamente, submetendo a uma estabilidade quanto a sua dinâmica das classes de usos. Já o ano de 2015, último analisado, mostrou que a supressão da vegetação nativa foi minimizada no período analisado, registrando inclusive um ligeiro aumento, chegando a $47,36 \%$ da área total. Este aumento também foi encontrado nas atividades agrícolas, chegando aos $18,10 \%$ da área acompanhado por uma interessante redução das pastagens $(24,79 \%)$. Assim como as outras classes, a área urbana também passou pelo processo de expansão, chegando a $8,47 \%$, e as áreas água também foram ampliadas devido ao surgimento de represamentos, chegando a cerca de $1,30 \%$.

\section{ANÁlise da RELAÇÃo da APTIDÃo Agrícola dAs TERRAS e da VEGETAÇÃo}

$A$ análise isolada dos remanescentes de vegetação nativa, integrada com a aptidão agrícola, mostrou proporcionalmente em quais classes estão às áreas preservadas observadas nos anos de 1985, 1995, 2005 e 2015 (Figura 4). Desta forma, a vegetação da Zona de Amortecimento do PESCAN sofreu grandes reduções desde o ano 1985, curiosamente os dados gerados sobre o uso do solo, apontam que os anos de 2005 e 2015 apresentaram valores muito próximos, inclusive sugerindo a regeneração e/ou recuperação de algumas áreas. 
Figura 4 - Mapas da evolução cronológica dos remanescentes do Cerrado na ZA do PESCAN (1985a 2015)
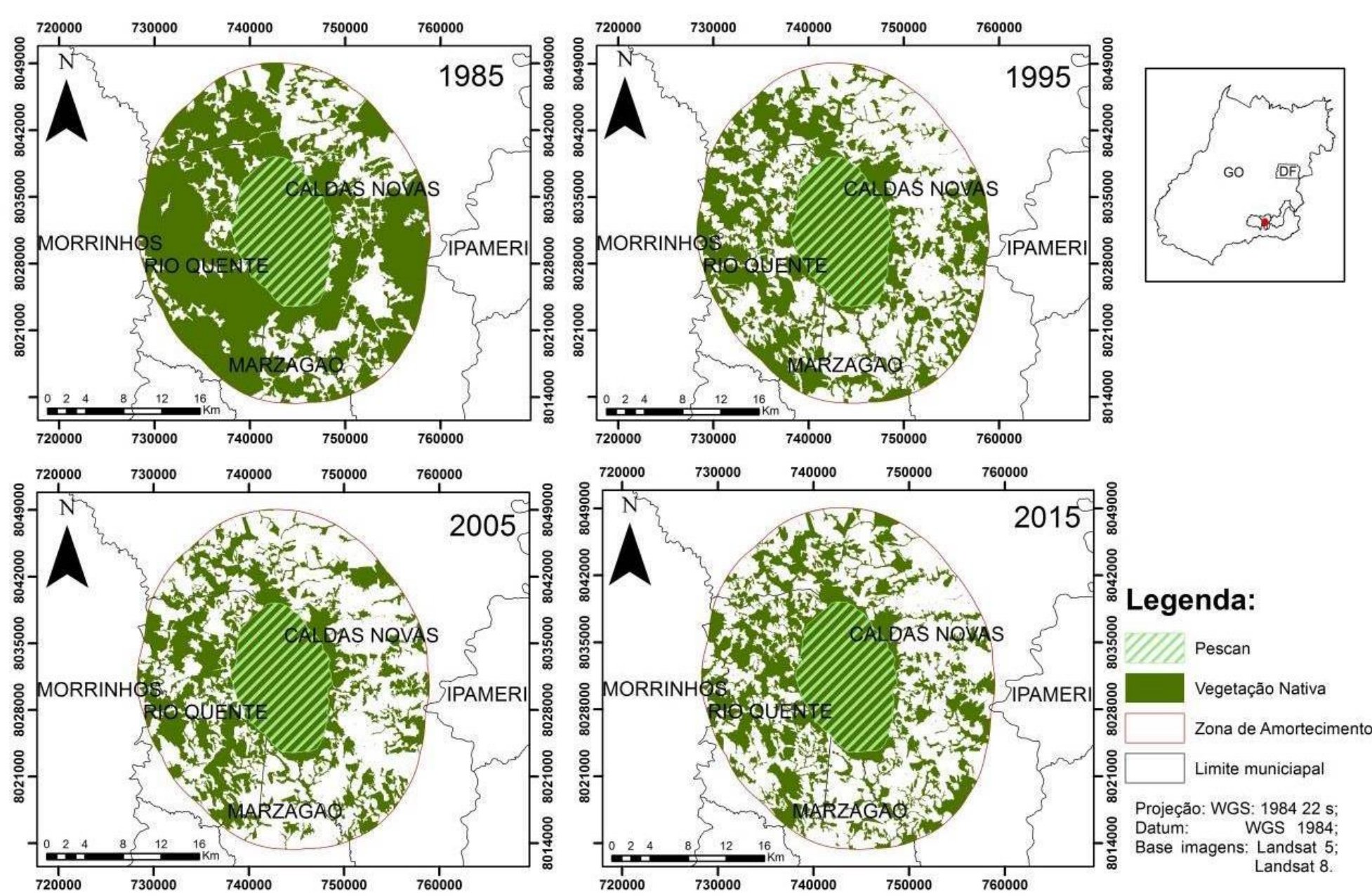

Fonte: elaborado pelos autores (2016) 
A DVAP em 1985 mostrou maior densidade de Cerrado nas áreas destinadas para uso de Pastagens Plantadas, totalizando $35,13 \%$, destacando-se a classe de aptidão agrícola $4 p$, com $22,23 \%$. Seguidamente, as classes recomendadas para Silvicultura e Pastagem Natural apresentaram a segunda maior densidade de vegetação no período, chegando a $24,67 \%$, evidenciando-se a $5 S$, com $13,20 \%$. Em sequência, surgiram as terras sem aptidão agrícola, a classe 6 , destinadas para Preservação, totalizando uma área de DVAP de $21,18 \%$. A menor área de densidade de vegetação pela aptidão agrícola são as áreas de destinadas às Lavouras, com 19,02\%

Em 1995 a DVAP também mostrou ligeiramente maior nas áreas de Pastagens Plantadas, cerca de $31,85 \%$, sendo também de destaque a classe $4 p$ com $20,58 \%$. Neste decênio, as áreas de aptidão voltada exclusivamente para Preservação, a classe 6 , apresentaram aumento na taxa de densidade de vegetação, chegando aos $29,41 \%$. A classe com aptidão destinada para a Silvicultura e Pastagem Natural apresentou o índice de 25,55\%, com predomínio nas áreas 5S (13,42\%). A menor proporção ocorreu também nas áreas com uso recomendado para lavouras que totalizou uma densidade de $13,21 \%$, apresentando queda em relação ao ano anterior.

Os valores do DVCS para o decênio de 2005 também reiteraram o padrão dos anos anteriores. As áreas de Pastagens Plantadas e de Preservação mantiveram-se como as classes aptidão com maior densidade de vegetação nativa, porém com aumento, chegando a $32,88 \%$ e a $32,49 \%$ respectivamente. Elas foram seguidas pelas Silviculturas e Pastagens Naturais atingindo o valor de $22,74 \%$. Neste período, as áreas com destinação para agricultura apresentaram uma densidade de $11,88 \%$, a menor valor de concentração de vegetação que registrou redução em relação ao período anterior.

O último decênio analisado, 2015, mostrou que a maior densidade de vegetação em relação à aptidão agrícola ocorreu na classe 6 , destinada para a preservação, com uma densidade de $32,03 \%$. As outras classes repetiram o padrão apresentado no período passado, seguindo a ordem das Pastagens Plantadas (30,01\%), Silvicultura e Pastagens Naturais $(23,39 \%)$ e Lavouras $(14,58 \%)$. Efetivamente, que as áreas de Preservação, incluindo a área do PESCAN, registrou o predomínio da DVAP na área de estudo, do qual pode estar associado com a regeneração natural da vegetação, com o aumento da fiscalização ou crises econômicas que pode ter motivado recessão produtiva.

As classes de aptidão agrícola, na ZA do PESCAN, com melhor potencial para o aproveitamento econômico, resultaram em menores índices de densidade de vegetação nativas, que é o caso evidenciado pelas áreas indicadas para lavouras, com as classes de aptidão $1 \mathrm{Abc}$, 2abc e 2ab(c), relacionadas com Latossolos Vermelho-Amarelos. A relação entre estas áreas e as classes de solos correlacionam-se com o avanço da fronteira agrícola que apresentou grande critério de seletividade para os solos com aptidão para agricultura motomecanizada. As áreas mais preservadas, em que se encontra maior densidade de Cerrado na região, foram centralizadas nas regiões de menor potencial para o aproveitamento econômico e nas áreas de unidade de conservação, destacando-se as classes de aptidão 4P, 4p, 5 (sn), 5S, 5n, 5s(n), 5sn e 6, associadas aos Argissolos Vermelho-Amarelos, aos Cambissolos Distróficos, Cambissolos Háplicos e aos Neossolos Litólicos e aos Latossolos VermelhoAmarelos localizados dentro da unidade de conservação.

\section{CONSIDERAÇÕES FINAIS}

Os resultados apresentados ao longo desta pesquisa revelaram a importância da criação das unidades de conservação, sobretudo o Parque Estadual Serra de Caldas Novas. A sua instalação incentivou o ordenamento do uso do solo nas áreas de recargas e ressurgências das águas termais, incentivando a proteção hídrica e florestal, agindo diante de um modelo sistêmico de preservação ambiental. Contudo, fora dos limites diretos do PESCAN, na Zona de Amortecimento, estabeleceu-se a perda dos recursos florestais, mostrando que o planejamento regional não estabeleceu com a mesma eficiência. Desse modo, foi possível observar que o uso do solo, nessas áreas, mostrou uma constante evolução principalmente da agricultura e da pecuária, em contrapartida com o retrocesso da vegetação nativa.

A relação das áreas preservadas mostrou grande influência pedológica por meio da aptidão agrícola, mais evidente com a relação da Densidade de Vegetação por Aptidão Agrícola (DVAP). As áreas com maior nível de preservação do Cerrado foram registradas nos solos com menor aptidão para a agricultura e nas áreas com restrições ambientais, como é o caso dos Argissolos Vermelho-Amarelos, Cambissolos Distróficos, Cambissolos Háplicos e dos Neossolos Litólicos. As áreas mais propícias para o uso agrícola estruturam-se em menores remanescentes, com exceção ao PESCAN que é

$\begin{array}{llllll}\text { Caminhos de Geografia } & \text { Uberlândia } & \text { v. 20, n. } 72 & \text { Dezembro/2019 } & \text { p. 01-14 } & \text { Página } 12\end{array}$


caracterizado pelos Latossolos Vermelho, mostrando-se eficiente na interferência na conservação dos remanescentes florestais nas áreas de domínio destas classes.

Também é importante considerar que parte das áreas recomendadas para preservação, de aptidão 6 , da qual foi inserida a unidade de conservação, insere-se em área com condições para abrigar agricultura mecanizada.

\section{REFERÊNCIAS}

BARBOSA, R. V. R.; VECCHIA, F. A. S. Estudos de ilha de calor urbana por meio de imagens do Landsat7 ETM+: Estudo de caso em São Carlos (SP). Revista Minerva, v. 6, p. 273-278, 2009.

BRASIL. Lei n. 9.985 de 18 de julho de 2000. Regulamenta o art. 225, § 10, incisos I, II, III e VII da Constituição Federal, institui o Sistema Nacional de Unidades de Conservação da Natureza e da outras providências. Disponível em:<http:// http://www.planalto.gov.br/ccivil_03/LEIS/L9985.htm>. Acesso em: 22 de dezembro. 2018.

CAMPOS, J. E. G.; TRÖGER, U.; HAESBAERT, F. F. Águas Quentes de Caldas Novas, Goiás Notável ocorrência de águas termais sem associação com magmatismo. In: WINGE, M. et al. (Org.) Sítios geológicos e paleontológicos do Brasil. Rio de janeiro: CPRM - CEDOC, 2009.p. 177-190.

COELHO, M.R. et al. O Recurso Natural Solo. In: MANZATTO, C.V; FREITAS JR., E; PERES, J.R.R. Uso Agrícola dos Solos Brasileiros. Rio de Janeiro: Embrapa Solos, 2002. p. 1-11.

COSTA, P.C. Unidades de Conservação: matéria-prima do ecoturismo. São Paulo: Aleph, 2002. (Série Turismo).

FEMAGO-FUNDAÇÃO ESTADUAL DE MEIO AMBIENTE DE GOIÁS. Plano de Manejo do Parque Estadual Serra de Caldas. Goiânia, 1997. 207 p. Documento técnico.

FERREIRA, M.; FERREIRA JR. L. G.; FERREIRA, N.C. Cobertura Vegetal Remanescente em Goiás: distribuição, viabilidade ecológica e monitoramento. In: FERREIRA JR. L.G. (Org). A Encruzilhada Socioambiental: biodiversidade, economia e sustentabilidade no cerrado. Goiânia: UFG, 2008. p.169-185.

INPE-INSTITUTO NACIONAL DE PESQUISAS ESPACIAIS. Banco de Dados Geomorfométricos do Brasil. Topodata. sd. Disponível em: < http://www.dsr.inpe.br/topodata/dados.php>. Acesso em: $10 \mathrm{de}$ setembro de 2018.

Catálogo de imagens. sd. Disponível em: <http://www.dgi.inpe.br/CDSR/>. Acesso em: 10 de setembro de 2018

KAGEYAMA, A. et al. O Novo Padrão Agrícola Brasileiro: do complexo rural aos complexos agroindustriais. In: DELGADO, G.C; GASQUES, J.G; VILLA VERDE, C.M (Org). Agricultura e Políticas Públicas. Brasília: IPEA,1996. p. 113-224.

MARTINS, J. S. Capitalismo e tradicionalismo: estudos sobre as contradições da sociedade agrária do Brasil. São Paulo. Pioneira,1975.

MENDES, P. C. B. Turismo e Meio Ambiente no Parque Estadual Serra de Caldas Novas-Go (PESCAN). Dissertação (Mestrado em Ecologia e Produção Sustentável) - Goiânia: Faculdade Católica de Goiás. 2007.

MIZIARA, F. Condições estruturais e opções individuais na formulação do conceito de fronteira agrícola. In: Luis Sérgio Duarte da Silva. (Org). Relações Cidade- Campo: fronteiras. Goiânia: UFG, 2000. p. 273280.

RAMALHO FILHO, A.; BEEK, K. J. Sistema de avaliação da aptidão agrícola das terras. 3. ed. rev. Rio de Janeiro: EMBRAPA-CNPS, 1995. 65 p.

REATTO, A. et al. Solos do Bioma Cerrado: aspectos pedológicos. In: SANO, S.; M; ALMEIDA, S. P.; RIBEIRO, J. F. Cerrado: ecologia e flora. Brasília: Embrapa, 2008. p. 107-149.

RUGGIERO, P. G. C. et al. Relação entre solo, vegetação e topografia em área de cerrado (Parque Estadual de Vassununga, SP): como se expressa em mapeamentos? Acta BotanicaBrasilica. Belo Horizonte, v. 2, p. 383-394, 2005. https://doi.org/10.1590/S0102-33062006000200013

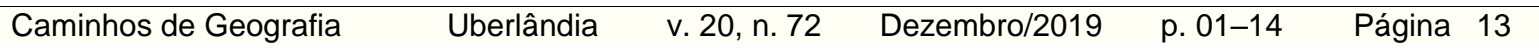


SANO, E. E. et al. Mapeamento Semidetalhado do uso da Terra do Bioma Cerrado. Pesquisa Agropecuária Brasileira. Brasília, v.43, p. 153-156. 2008. https://doi.org/10.1590/S0100$\underline{204 X 2008000100020}$

SIEG-Sistema Estadual de Geoinformação. Sistema de Informações Geográficas de Goiás-Shapefile. 2016. Disponível em: <http://www.sieg.go.gov.br/>. Acesso em 20 de setembro de 2018.

SILVA, J. R.; FERREIRA, N. C. Análise do Turismo Ambiental em Municípios Goianos. Boletim Goiano de Geografia. Goiânia, v. 31, p. 129-148, 2011. https://doi.org/10.5216/bgg.v31i1.15404

SILVA, R. B. M. et al. Relação Solo/Vegetação em Ambiente de Cerrado Sobre Influência do Grupo Urucuia. Ciência Florestal, Santa Maria, v.25, p. 363-373, 2015. https://doi.org/10.5902/1980509818455

Recebido em: 07/02/2018

Aceito para publicação em: 24/10/2019 